\title{
Solid Ammonia Charging by Low-Energy Electrons
}

\author{
Roey Sagi, Michelle Akerman, Sujith Ramakrishnan, and Micha Asscher* \\ Institute of Chemistry, Edmond J. Safra Campus, Givat-Ram, The Hebrew University \\ of Jerusalem, Jerusalem 9190401, Israel \\ E-mail of corresponding author: micha.asscher@mail.huji.ac.il
}

\section{Supporting Information}

The following sections support the results presented in the main text. The following includes supplementary data on the effects of incident electron beam current (Section 1), electron kinetic energy (Section 2), the transmission current reproducibility and charging decay during stability assessments (Section 3), a fullscale TP- $\triangle$ CPD measurement of a non-charged ammonia film (Section 4), the effect of irradiation temperature (Section 5), the effect of ammonia film thickness (Section 6), and discusses the correlation between $\triangle \mathrm{CPD}$ and the level of film charging (Section 7). 


\section{Incident Electron Beam Current}
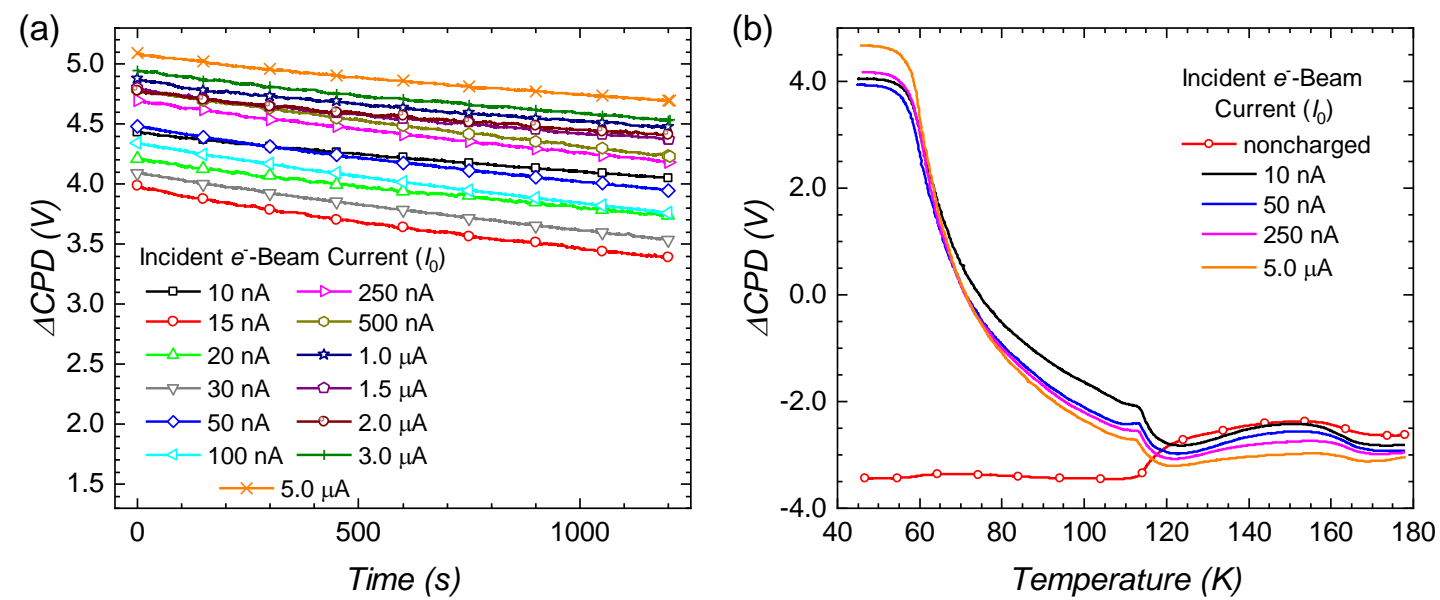

Figure S1. Incident electron-beam transmission current-dependent charging of 3300 ML-thick amorphous solid ammonia (ASA) films grown at $45 \mathrm{~K}$. These films were subsequently irradiated (at $45 \mathrm{~K}$ ) by $4 \mathrm{eV}$ electrons at the indicated incident through-the-bare $\mathrm{Ru}(0001)$ substrate electron transmission current $\left(I_{0}\right)$ range of $10 \mathrm{nA}$ to $5 \mu \mathrm{A}$ (see Figure 1 of the main text). (a) Charging stability $\triangle$ CPD measurements for the indicated $I_{0}$ values. (b) Temperature programmed $\triangle \mathrm{CPD}$ (TP- $\Delta \mathrm{CPD})$ profiles recorded during the subsequent annealing of the charged films at a heating rate of $1 \mathrm{~K} / \mathrm{s}$ (only a few are shown for clarity). A non-charged film serves as a reference for comparison. 


\section{Electron Kinetic Energy}

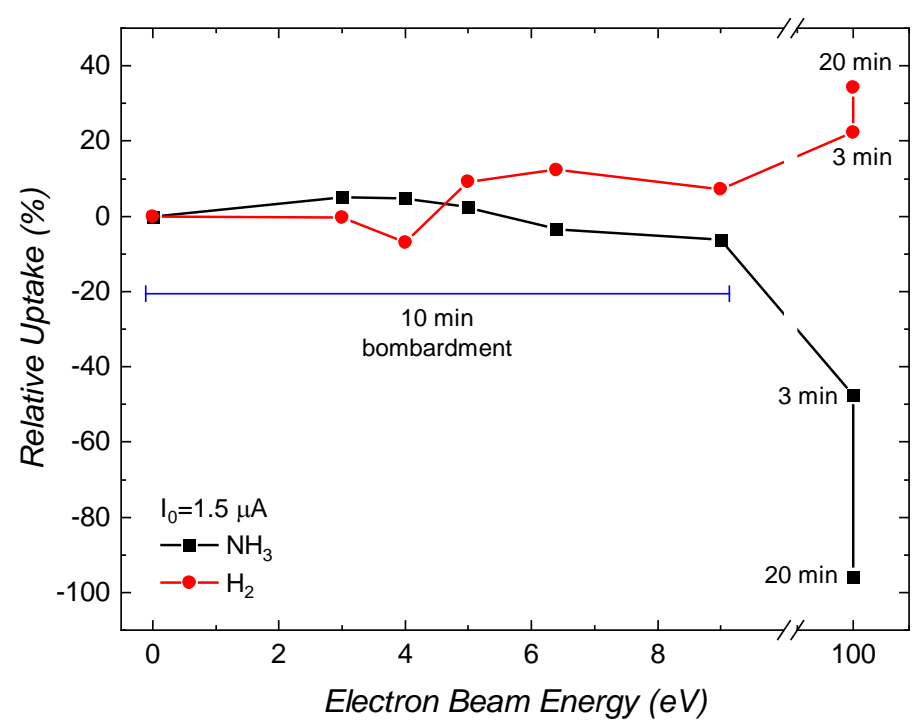

Figure S2. Electron kinetic energy effect on dissociation of ammonia molecules in 40 ML-thick ammonia layer grown at $30 \mathrm{~K}$ and bombarded by electrons (at $30 \mathrm{~K}$ as well) at $I_{0}=1.5 \mu \mathrm{A}$ at varied energies. In black squares and red circles are the normalized uptakes of $\mathrm{NH}_{3}(\mathrm{~m} / \mathrm{z}=17)$ and $\mathrm{H}_{2}(\mathrm{~m} / \mathrm{z}=2) \Delta \mathrm{P}$-TPD measurements following the electron bombardment. An error of $10 \%$ is estimated for each data point. The molecular ammonia films were irradiated for $10 \mathrm{~min}$, except those irradiated at $100 \mathrm{eV}$ that were irradiated for 3 and $20 \mathrm{~min}$. 

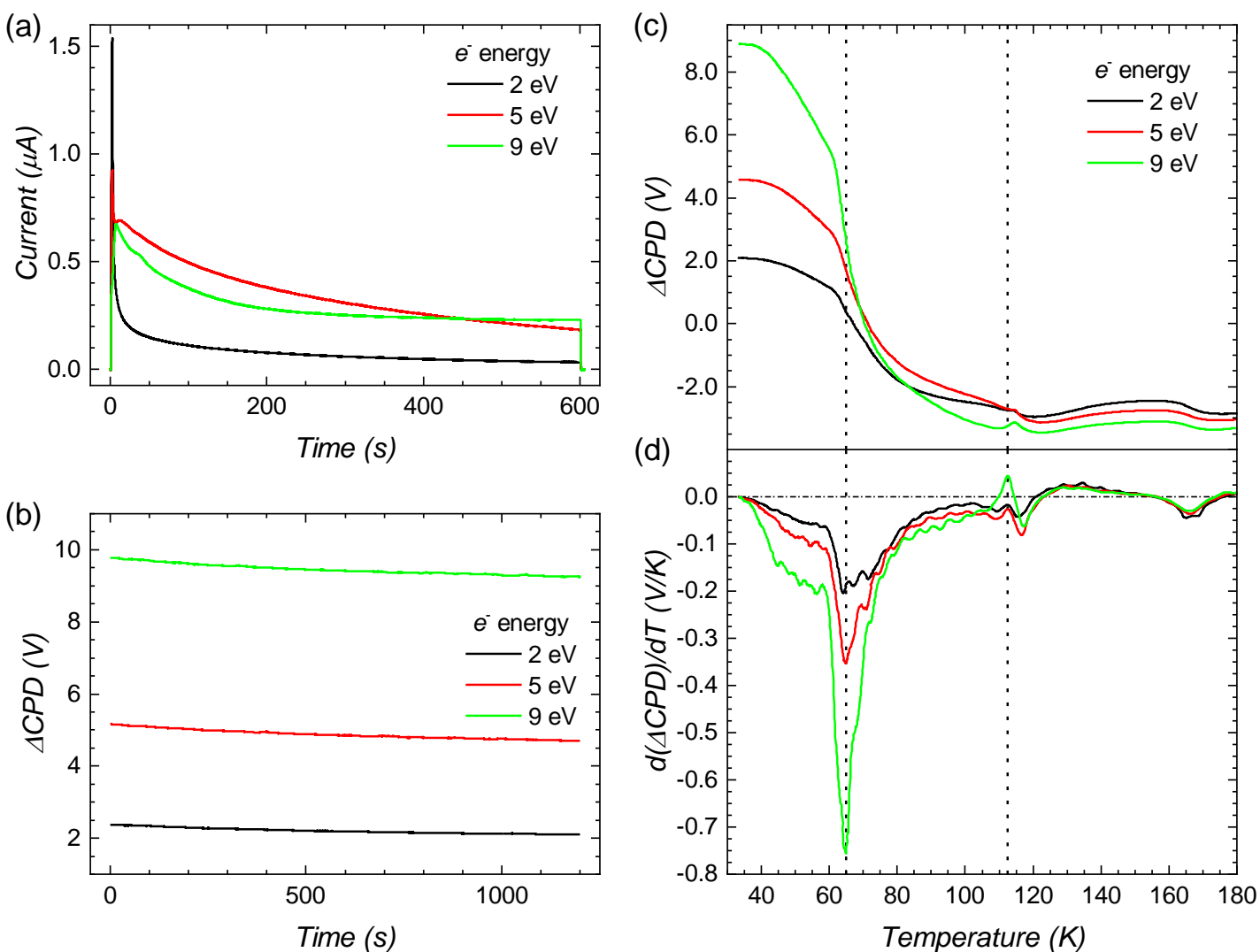

Figure S3. Electron kinetic energy dependent charging of 3300 ML-thick ASA films grown at 50 $\mathrm{K}$ and irradiated by electrons at kinetic energies in the range of $2-9 \mathrm{eV}$ at $I_{0}=1.5 \mu \mathrm{A}$ and at $T_{\text {irr }}=30 \mathrm{~K}$. Through-the-film transmission currents (a), the following charging stability $\triangle \mathrm{CPD}$ measurements (b), the subsequent TP- $\Delta$ CPD measurements (c), and their temperature derivative $[d(\Delta C P D) / d T]$ spectra (d). All these measurements demonstrate the electron kinetic energy dependence of the film charging and discharging, namely the kinetic energy affects the films' charging level but not the binding energetics of the trapped electrons, as peaks are obtained at the same temperatures. 


\section{Current Measurements Reproducibility and the Effect of Charging Stability}
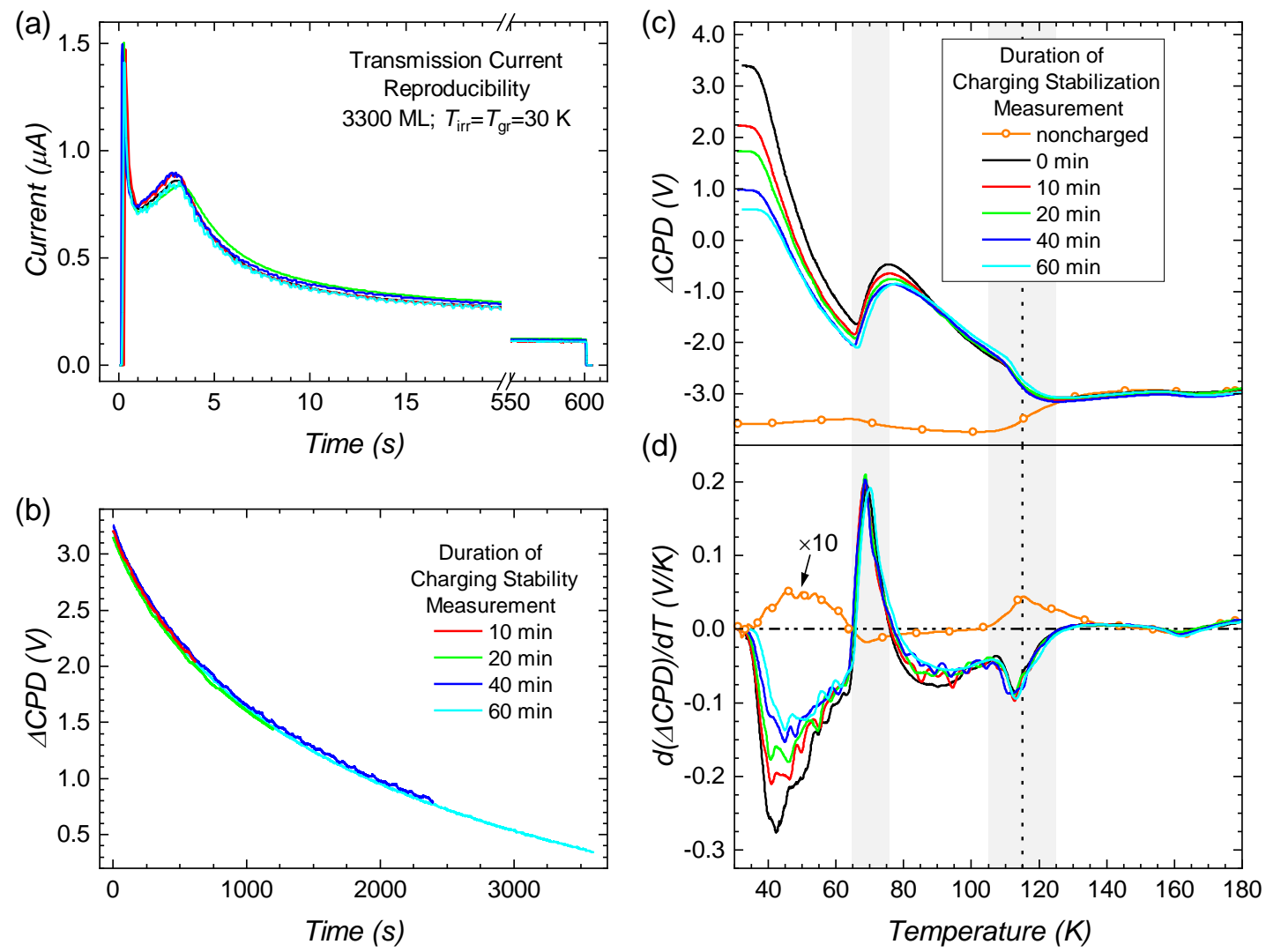

Figure S4. Reproducibility of current measurements and charging decay with time. Transmission current reproducibility of five identical transmission measurements (a), charging stability $\triangle$ CPD measurements performed for various durations (b), the dependence of the TP- $\Delta$ CPD profiles (c) and their $\mathrm{d}(\triangle \mathrm{CPD}) / \mathrm{dT}$ spectra (d) on the duration of the charging stability measurements described in (b). All films were 3300 ML-thick ASA grown at $30 \mathrm{~K}$ and irradiated (also at $30 \mathrm{~K}$ ) by $4 \mathrm{eV}$ electrons at $I_{0}=1.5 \mu \mathrm{A}$. The duration of the charging stability measurements mostly affects the low-temperature peak of the $\mathrm{d}(\triangle \mathrm{CPD}) / \mathrm{dT}$ spectra, implying the decay of the electron population trapped at low-energy surface sites. 


\section{Full-Scale TP- $\triangle$ CPD Measurement of a Non-Charged Film}

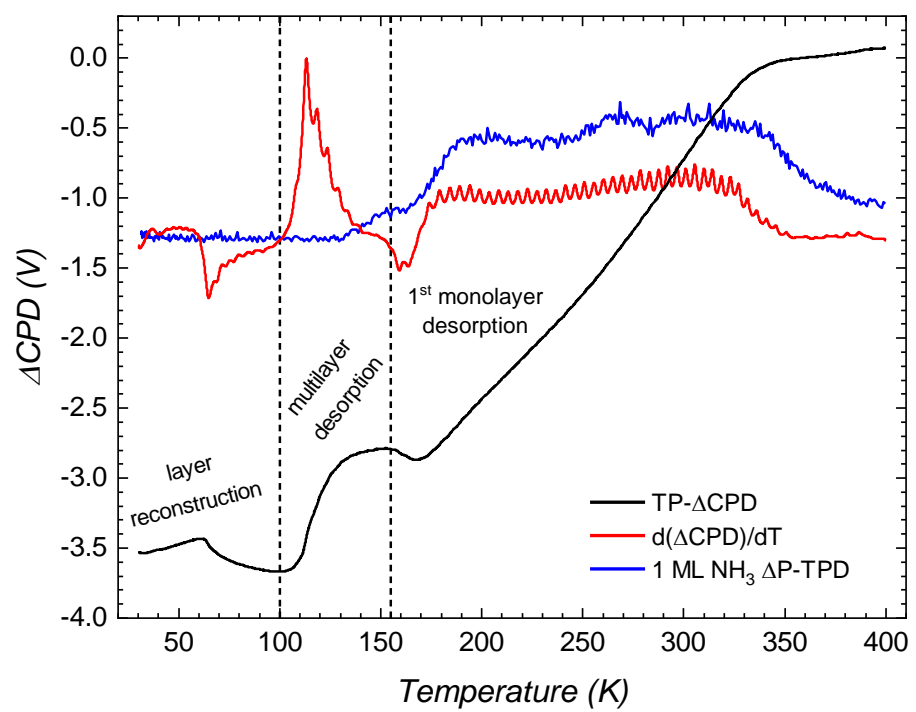

Figure S5. TP- $\triangle$ CPD measurement of 3300 ML-thick non-charged ammonia film grown at $30 \mathrm{~K}$ (in black; heating rate of $1 \mathrm{~K} / \mathrm{s})$. The desorption of the first monolayer from the $\mathrm{Ru}(0001)$ surface terminates at $\sim 350 \mathrm{~K}$. The corresponding $\mathrm{d}(\Delta \mathrm{CPD}) / \mathrm{dT}$ spectrum is also demonstrated (in red) together with a 1 ML-thick ammonia layer $\triangle \mathrm{P}$-TPD spectrum (in blue; heating rate of $4 \mathrm{~K} / \mathrm{s}$ ). TP$\Delta$ CPD and $\triangle$ P-TPD measurements are closely related and by many aspects are complementary. If no competing interaction with the surface takes place, the voltage recorded during TP- $\Delta C P D$ measurement provides a measure of the coverage left on the surface at each stage of desorption, which in the case of ammonia the multilayer desorption begins at $85 \mathrm{~K}$. Thus, its temperature derivative [the $\mathrm{d}(\triangle \mathrm{CPD}) / \mathrm{dT}$ spectrum] is directly proportional to the desorption rate recorded during $\triangle$ P-TPD measurement. ${ }^{\mathrm{S} 1}$ In principle, TP- $\Delta$ CPD measurements can also track surface and dielectric phenomena that alter the surface charge distribution and occur prior to any desorption, e.g., molecular reorientations in the case of polar adsorbates and discharge, reflected in this work during pore collapse and crystallization. Minor variations of the $\triangle \mathrm{P}-\mathrm{TPD}$ and $\mathrm{d}(\Delta \mathrm{CPD}) / \mathrm{dT}$ profiles are due to the different heating rates used. 


\section{Irradiation Temperature Effect on Film Charging and Discharging}
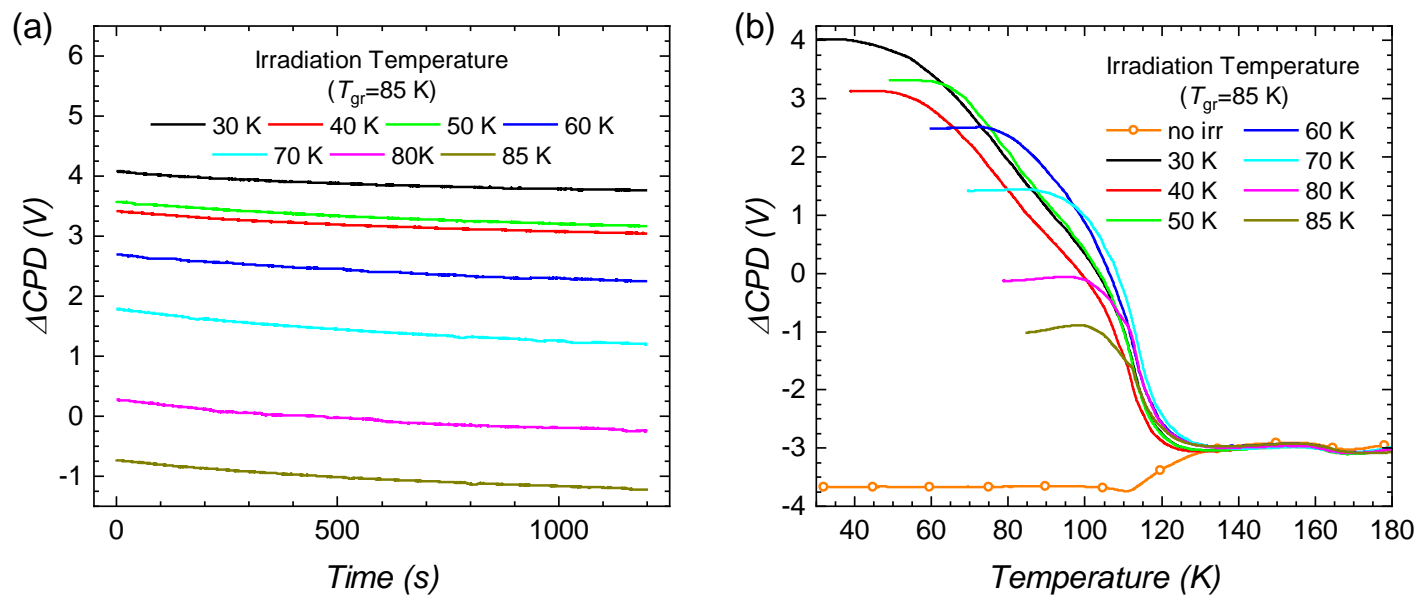

Figure S6. Irradiation temperature effect $\left(T_{\text {irr }}\right.$ in the range of 30-85 K). All films were $3300 \mathrm{ML}$ thick crystalline ammonia grown at $85 \mathrm{~K}$ and irradiated by $4 \mathrm{eV}$ electrons at $I_{0}=1.5 \mu \mathrm{A}$ for 10 min. (a) Charging stability $\Delta$ CPD measurements. (b) Subsequent TP- $\Delta$ CPD measurements. The corresponding current profiles and the $\mathrm{d}(\Delta \mathrm{CPD}) / \mathrm{dT}$ spectra are presented in Figure 5 of the main text.

\section{Thickness Effect on Film Charging}
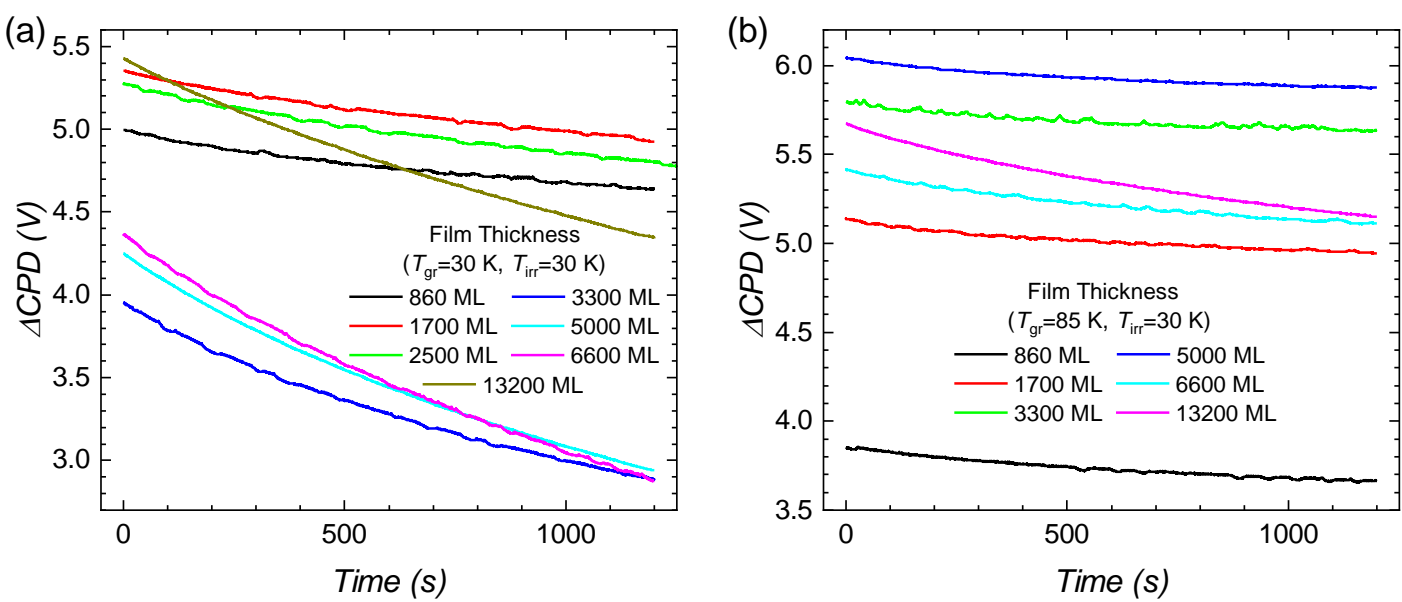

Figure S7. The effect of film thickness on the charging of ammonia films. Charging stability $\triangle \mathrm{CPD}$ measurements of films grown at $30 \mathrm{~K}$ (a) and $85 \mathrm{~K}$ (b), irradiated by $4 \mathrm{eV}$ electrons at $I_{0}=1.5 \mu \mathrm{A}$ and at $T_{\mathrm{irr}}=30 \mathrm{~K}$ until the saturation of the current profile was reached (Figure 6 of the main text). 


\section{Correlating the Measured $\triangle \mathrm{CPD}$ and Level of Film Charging}

The sign of the surface potential, typically denoted $V_{\text {film }}$ is a matter of convention, as its direction is traditionally taken from the negative charge toward the positive one. We consider the film charging according to the measured $\triangle \mathrm{CPD}$ following the bombardment of the film with charges. From the definition of $\triangle \mathrm{CPD}$, this measurement is relative to CPD of the bare substrate (thus to its work function), and is calculated here by:

$$
C P D=\Phi_{\text {sample }}-\Phi_{\text {probe }}
$$

where $\Phi$ is the work function of either the sample or the probe, which are typically not determined/unknown (at least that of the probe), however are also not required. Thus,

$$
\begin{gathered}
\Delta C P D(t)=C P D(t)-C P D_{0}=\Phi_{\text {sample }}(t)-\Phi_{\text {bare sample }} \\
=\Delta \Phi_{\text {substrate } / \text { film interface }}-V_{\text {film }}(t) .
\end{gathered}
$$

The $\triangle \mathrm{CPD}$ is thus defined in the framework of the substrate and shows an opposite trend (sign of the slope) to the actual film's surface potential $V_{\text {film. }}$ One should, nevertheless, consider that $V_{\text {film }}$ accounts not only the potential difference developed due to film charging ( $\Delta \mathrm{V}$ in the main text) but also any spontaneous development of polarization during film growth and is their superposition.

\section{References}

(S1) Engelhardt, H. A.; Feulner, P.; Pfnür, H.; Menzel, D. An accurate and versatile vibrating capacitor for surface and adsorption studies. J. Phys. E: Sci. Instrum. 1977, $10(11), 1133$. 